\title{
Reagent and laboratory contamination can critically impact sequence-based microbiome analyses
}

\author{
Susannah J Salter ${ }^{*}$, Michael J Cox², Elena M Turek², Szymon T Calus ${ }^{3}$, William O Cookson², Miriam F Moffatt ${ }^{2}$,
} Paul Turner ${ }^{4,5}$, Julian Parkhill ${ }^{1}$, Nicholas J Loman ${ }^{3}$ and Alan W Walker ${ }^{1,6^{*}}$

\begin{abstract}
Background: The study of microbial communities has been revolutionised in recent years by the widespread adoption of culture independent analytical techniques such as $16 \mathrm{~S}$ rRNA gene sequencing and metagenomics. One potential confounder of these sequence-based approaches is the presence of contamination in DNA extraction kits and other laboratory reagents.

Results: In this study we demonstrate that contaminating DNA is ubiquitous in commonly used DNA extraction kits and other laboratory reagents, varies greatly in composition between different kits and kit batches, and that this contamination critically impacts results obtained from samples containing a low microbial biomass. Contamination impacts both PCR-based 165 rRNA gene surveys and shotgun metagenomics. We provide an extensive list of potential contaminating genera, and guidelines on how to mitigate the effects of contamination.

Conclusions: These results suggest that caution should be advised when applying sequence-based techniques to the study of microbiota present in low biomass environments. Concurrent sequencing of negative control samples is strongly advised.
\end{abstract}

Keywords: Contamination, Microbiome, Microbiota, Metagenomics, 165 rRNA

\section{Background}

Culture-independent studies of microbial communities are revolutionising our understanding of microbiology and revealing exquisite interactions between microbes, animals and plants. Two widely used techniques are deep sequence surveying of PCR-amplified marker genes such as 16S rRNA, or whole-genome shotgun metagenomics, where the entire complement of community DNA is sequenced en masse. While both of these approaches are powerful, they have important technical caveats and limitations, which may distort taxonomic distributions and frequencies observed in the sequence dataset. Such limitations, which have been well reported in the literature, include choices relating to sample collection, sample storage and preservation, DNA extraction, amplifying primers,

\footnotetext{
*Correspondence: sb18@sanger.ac.uk; alan.walker@abdn.ac.uk

'Pathogen Genomics Group, Wellcome Trust Sanger Institute, Hinxton, UK ${ }^{6}$ Microbiology Group, Rowett Institute of Nutrition and Health, University of Aberdeen, Aberdeen, UK

Full list of author information is available at the end of the article
}

sequencing technology, read length and depth and bioinformatics analysis techniques $[1,2]$.

A related additional problem is the introduction of contaminating microbial DNA during sample preparation. Possible sources of DNA contamination include molecular biology grade water [3-9], PCR reagents [10-15] and DNA extraction kits themselves [16]. Contaminating sequences matching water- and soilassociated bacterial genera including Acinetobacter, Alcaligenes, Bacillus, Bradyrhizobium, Herbaspirillum, Legionella, Leifsonia, Mesorhizobium, Methylobacterium, Microbacterium, Novosphingobium, Pseudomonas, Ralstonia, Sphingomonas, Stenotrophomonas and Xanthomonas have been reported previously $[3-15,17,18]$. The presence of contaminating DNA is a particular challenge for researchers working with samples containing a low microbial biomass. In these cases, the low amount of starting material may be effectively swamped by the contaminating DNA and generate misleading results. 
Although the presence of such contaminating DNA has been reported in the literature, usually associated with PCR-based studies, its possible impact on high-throughput $16 \mathrm{~S}$ rRNA gene-based profiling and shotgun metagenomics studies has not been reported. In our laboratories we routinely sequence negative controls, consisting of 'blank' DNA extractions and subsequent PCR amplifications. Despite adding no sample template at the DNA extraction step, these negative control samples often yield a range of contaminating bacterial species (see Table 1), which are often also visible in the human-derived samples that are processed concomitantly with the same batch of DNA extraction kits. The presence of contaminating sequences is greater in low-biomass samples (such as from blood or the lung) than in high-biomass samples (such as from faeces), suggesting that there is a critical tipping point where contaminating DNA becomes dominant in sequence libraries.

Many recent publications [19-37] describe important or core microbiota members, often members that are biologically unexpected, which overlap with previouslydescribed contaminant genera. Spurred by this and by the results from negative control samples in our own laboratories when dealing with low-input DNA samples, we investigated the impact of contamination on microbiota studies and explored methods to limit the impact of such contamination. In this study we identify the range of contaminants present in commonly used DNA extraction reagents and demonstrate the significant impact they can have on microbiota studies.

\section{Results}

\section{S rRNA gene sequencing of a pure Salmonella bongori} culture

To demonstrate the presence of contaminating DNA and its impact on high and low biomass samples, we used $16 \mathrm{~S}$ rRNA gene sequence profiling of a pure culture of Salmonella bongori that had undergone five rounds of serial ten-fold dilutions (equating to a range of approximately $10^{8}$ cells as input for DNA extraction in the original undiluted sample, to $10^{3}$ cells in dilution five). S. bongori was chosen because we have not observed it as a contaminant in any of our previous studies and it can be differentiated from other Salmonella species by $16 \mathrm{~S}$ rRNA gene sequencing. As a pure culture was used as starting template, regardless of starting biomass, any organisms other than $S$. bongori observed in subsequent DNA sequencing results must therefore be derived from contamination. Aliquots from the dilution series were sent to three institutes (Imperial College London, ICL; University of Birmingham, UB; Wellcome Trust Sanger Institute, WTSI) and processed with different batches of the FastDNA SPIN Kit for Soil (kit FP). 16S rRNA gene amplicons were generated using both 20 and 40 PCR cycles and returned to WTSI for Illumina MiSeq sequencing.

Table 1 List of contaminant genera detected in sequenced negative 'blank' controls

\begin{tabular}{|c|c|}
\hline Phylum & List of constituent contaminant genera \\
\hline \multirow[t]{6}{*}{ Proteobacteria } & Alpha-proteobacteria: \\
\hline & $\begin{array}{l}\text { Afipia, Aquabacterium }{ }^{e} \text {, Asticcacaulis, Aurantimonas, Beijerinckia, Bosea, Bradyrhizobium }{ }^{d} \text {, Brevundimonas }{ }^{c} \text {, Caulobacter, } \\
\text { Craurococcus, Devosia, Hoeflea }{ }^{e} \text {, Mesorhizobium, Methylobacterium }{ }^{c} \text {, Novosphingobium, Ochrobactrum, Paracoccus, Pedomicrobium, } \\
\text { Phyllobacterium }^{\mathrm{e}} \text {, Rhizobium }{ }^{c, d} \text {, Roseomonas, Sphingobium, Sphingomonas }{ }^{c, d, e} \text {, Sphingopyxis }\end{array}$ \\
\hline & Beta-proteobacteria: \\
\hline & 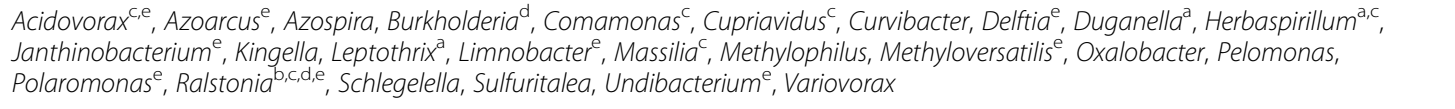 \\
\hline & Gamma-proteobacteria: \\
\hline & $\begin{array}{l}\text { Acinetobacter }{ }^{\mathrm{a}, \mathrm{d}, \mathrm{c}}, \text { Enhydrobacter, Enterobacter, Escherichia }^{\mathrm{a}, \mathrm{c}, \mathrm{d}, \mathrm{e}}, \text { Nevskia }^{\mathrm{e}}, \text { Pseudomonas }^{\mathrm{b}, \mathrm{d}, \mathrm{e}}, \text { Pseudoxanthomonas, Psychrobacter, } \\
\text { Stenotrophomonas }{ }^{\mathrm{a}, \mathrm{b}, \mathrm{c}, \mathrm{d}, \mathrm{e}}, \text { Xanthomonas }\end{array}$ \\
\hline Actinobacteria & $\begin{array}{l}\text { Aeromicrobium, Arthrobacter, Beutenbergia, Brevibacterium, Corynebacterium, Curtobacterium, Dietzia, Geodermatophilus, Janibacter, } \\
\text { Kocuria, Microbacterium, Micrococcus, Microlunatus, Patulibacter, Propionibacterium }{ }^{\text {, }} \text {, Rhodococcus, Tsukamurella }\end{array}$ \\
\hline Firmicutes & Abiotrophia, Bacillus', Brevibacillus, Brochothrix, Facklamia, Paenibacillus, Streptococcus \\
\hline Bacteroidetes & Chryseobacterium, Dyadobacter, Flavobacterium', Hydrotalea, Niastella, Olivibacter, Pedobacter, Wautersiella \\
\hline $\begin{array}{l}\text { Deinococcus- } \\
\text { Thermus }\end{array}$ & Deinococcus \\
\hline Acidobacteria & Predominantly unclassified Acidobacteria Gp2 organisms \\
\hline
\end{tabular}


$S$. bongori was the sole organism identified in the original undiluted culture but with subsequent dilutions a range of contaminating bacterial groups increased in relative abundance while the proportion of $S$. bongori reads concurrently decreased (Figure 1). By the fifth serial dilution, equivalent to an input biomass of roughly $10^{3}$ Salmonella cells, contamination was the dominant feature of the sequencing results. This pattern was consistent across all three sites and was most pronounced with $40 \mathrm{cy}$ cles of PCR. These results highlight a key problem with low biomass samples. The most diluted 20-PCR cycle samples resulted in low PCR product yields, leading to under-representation in the multiplexed pool of samples for sequencing as an equimolar mix could not be achieved (read counts for each sample are listed in Additional file 1: Table S1a). Conversely, using 40 PCR cycles generated enough PCR products for effective sequencing (a minimum of at least 14,000 reads per sample were returned, see Additional file 1: Table S1a), but a significant proportion of the resulting sequence data was derived from

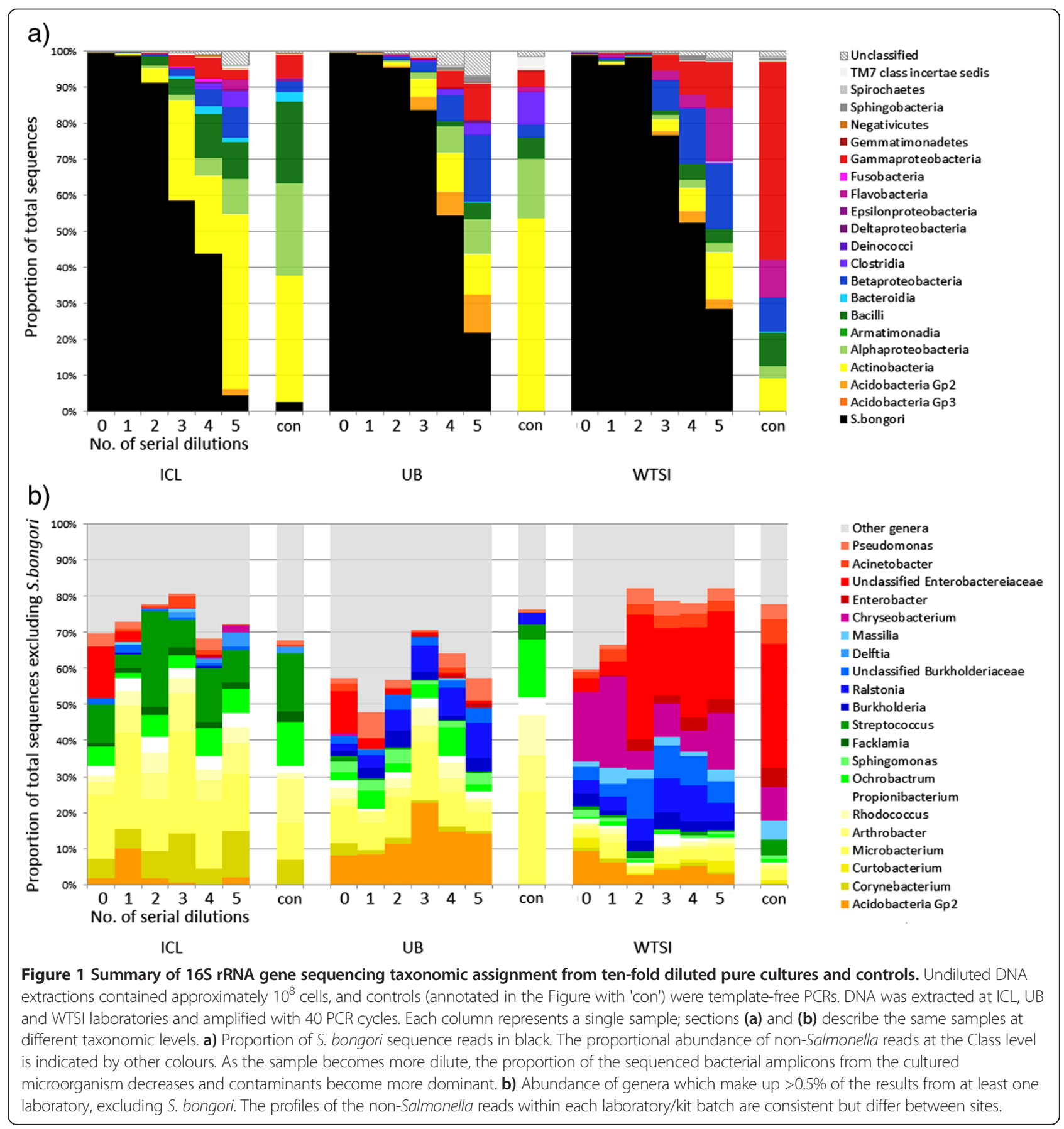


contaminating, non-Salmonella, DNA. It should be noted though that even when using only 20 PCR cycles contamination was still predominant with the lowest input biomass [see Additional file 1: Figure S1].

Sequence profiles revealed some similar taxonomic classifications between all sites, including Acidobacteria Gp2, Microbacterium, Propionibacterium and Pseudomonas (Figure 1b). Differences between sites were observed, however, with Chryseobacterium, Enterobacter and Massilia more dominant at WTSI, Sphingomonas at UB, and Corynebacterium, Facklamia and Streptococcus at ICL, along with a greater proportion of Actinobacteria in general (Figure 1a). This illustrates that there is variation in contaminant content between laboratories, which may be due to differences between reagent/kit batches or contaminants introduced from the wider laboratory environment. Many of the contaminating operational taxonomic units (OTUs) represent bacterial genera normally found in soil and water, for example Arthrobacter, Burkholderia, Chryseobacterium, Ochrobactrum, Pseudomonas, Ralstonia, Rhodococcus and Sphingomonas, while others, such as Corynebacterium, Propionibacterium and Streptococcus, are common human skin-associated organisms. By sequencing PCR 'blank' negative controls, specifically PCRamplified ultrapure water with no template DNA added, we were able to distinguish between taxa that had originated from the DNA extraction kits as opposed to DNA from other sources (such as PCR kit reagents, laboratory consumables or laboratory personnel). Sixty-three taxa were absent from all PCR blank controls but present at $>0.1 \%$ proportional abundance in one or more seriallydiluted S. bongori samples [see Additional file 1: Figure S2], suggesting that they were introduced to the samples at the DNA extraction stage. These include several abundant genera observed at all three sites, such as Acidobacteria Gp2, Burkholderia, unclassified Burkholderiaceae and Mesorhizobium. It also includes taxa, such as Hydrotalea and Bradyrhizobium, that were only abundant in samples processed by one or two sites, possibly indicative of variation in contaminants between different batches of the same type of DNA extraction kit.

\section{Quantitative PCR of bacterial biomass}

To assess how much background bacterial DNA was present in the samples, we performed qPCR of bacterial $16 \mathrm{~S}$ rRNA genes and calculated the copy number of genes present with reference to a standard curve. Assuming a complete absence of contamination, copy number of the $16 \mathrm{~S}$ rRNA genes present should correlate with dilution of $S$. bongori and reduce in a linear manner. However, at the third dilution copy number remained stable and did not reduce further, indicating the presence of background DNA at approximately 500 copies per $\mu$ l of elution volume from the DNA extraction kit (Figure 2).

\section{Shotgun metagenomics of a pure S. bongori culture processed with four commercial DNA extraction kits}

Having established that $16 \mathrm{~S}$ rRNA gene sequencing results can be confounded by contaminating DNA, we next investigated whether similar patterns emerge in shotgun metagenomics studies, which do not involve a targeted PCR step. We hypothesised that if contamination arises from the DNA extraction kit, it should also be present in metagenomic sequencing results. DNA extraction kits from four different manufacturers were used in order to investigate whether or not the problem was limited to a single manufacturer. Aliquots from the same $S$. bongori dilution series were processed at UB with the FastDNA SPIN Kit for Soil (FP), MoBio UltraClean Microbial DNA Isolation Kit (MB), QIAmp DNA Stool Mini Kit (QIA) and PSP Spin Stool DNA Plus kit (PSP). As with 16S rRNA gene sequencing, it was found that as the sample dilution increased, the proportion of reads mapping to the $S$. bongori reference genome sequence decreased (Figure 3a). Regardless of kit, contamination was always the predominant feature of the sequence data by the fourth serial dilution, which equated to an input of around $10^{4}$ Salmonella cells.

Samples were processed concurrently within the same laboratory. If the contamination was derived from the laboratory environment then similar bacterial compositions would be expected in each of the results. Instead, a range of environmental bacteria was observed, which were of a different profile in each kit (Figure 3b). FP had a stable kit profile dominated by Burkholderia, PSP was dominated by Bradyrhizobium, while the QIA kit had the most complex mix of bacterial DNA. Bradyrhizobiaceae, Burkholderiaceae, Chitinophagaceae, Comomonadaceae, Propionibacteriaceae and Pseudomonadaceae were present in at least three quarters of the dilutions from PSP, FP and QIA kits. However, relative abundances of taxa at the Family level varied according to kit: FP was marked by Burkholderiaceae and Enterobacteriaceae, PSP was marked by Bradyrhizobiaceae and Chitinophagaceae. The contamination in the QIA kit was relatively diverse in comparison to the other kits, and included higher proportions of Aerococcaceae, Bacillaceae, Flavobacteriaceae, Microbacteriaceae, Paenibacillaceae, Planctomycetaceae and Polyangiaceae than the other kits. Kit MB did not have a distinct contaminant profile. This was likely a result of the very low number of reads sequenced, with 210 reads in dilution 2, 79 reads in dilution 3 and fewer than 20 reads in subsequent dilutions [see Additional file 1: Table S1b]. Although read count is only a semi-quantitative measure of DNA concentration, this may indicate that levels of background 


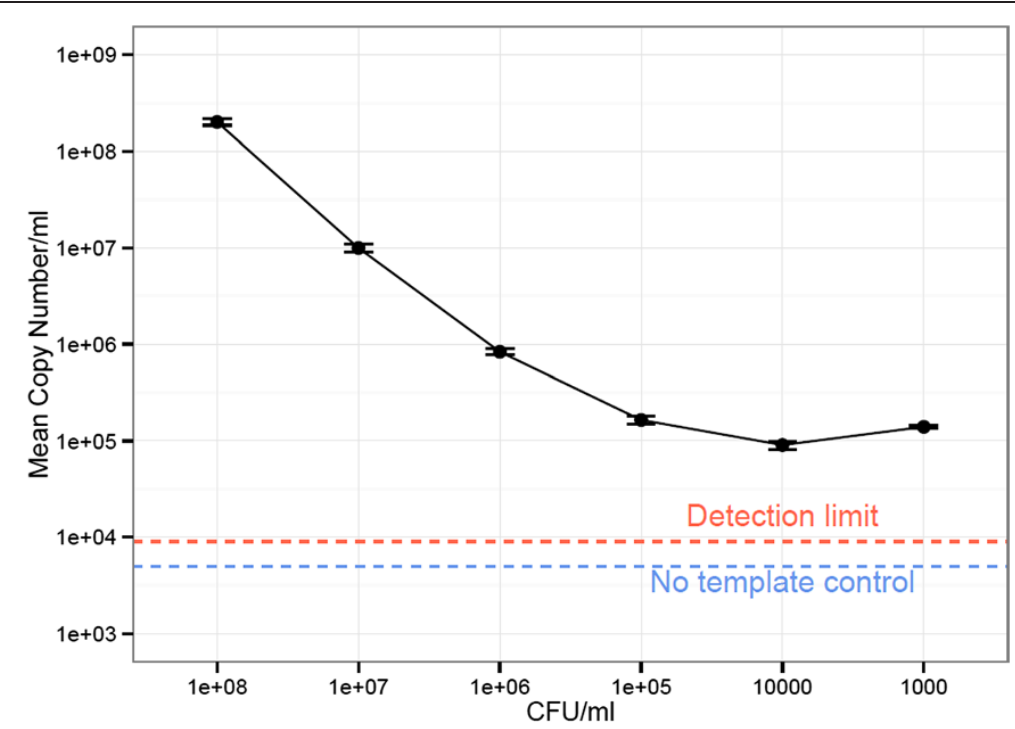

Figure 2 Copy number of total $16 \mathrm{~S}$ rRNA genes present in a dilution series of $\boldsymbol{S}$. bongori culture. Total bacterial DNA present in serial ten-fold dilutions of a pure S. bongori culture was quantified using GPCR. While the copy number initially reduces in tandem with increased dilution, plateauing after four dilutions indicates consistent background levels of contaminating DNA. Error bars indicate standard deviation of triplicate reactions. The broken red line indicates the detection limit of 45 copies of $16 \mathrm{~S}$ rRNA genes. The no template internal control for the qPCR reactions (shown in blue) was below the cycle threshold selected for interpreting the fluorescence values (that is, less than 0 ), indicating the contamination did not come from the qPCR reagents themselves.

contamination from this kit were comparatively lower than the other kits tested.

Comparatively few contaminant taxa that were detected in the 'blank' water control, which was dominated by Pseudomonas, were detected in the serially diluted metagenomic samples. This provided further evidence that the observed contamination was likely to have originated in large part from the DNA extraction kits themselves. These metagenomic results, therefore, clearly show that contamination becomes the dominant feature of sequence data from low biomass samples, and that the kit used to extract DNA can have an impact on the observed bacterial diversity, even in the absence of a PCR amplification step. Reducing input biomass again increases the impact of these contaminants upon the observed microbiota.

\section{Impact of contaminated extraction kits on a study of low-biomass microbiota}

Having established that the contamination in different lots of DNA extraction kits is not constant or predictable, we next show the impact that this can have on real datasets. A recent study in a refugee camp on the border between Thailand and Burma used an existing nasopharyngeal swab archive [38] to examine the development of the infant nasopharyngeal microbiota. A cohort of 20 children born in 2007/2008 were sampled every month until two years of age, and the 16S rRNA gene profiles of these swabs were sequenced by 454 pyrosequencing.
Principal coordinate analysis ( $\mathrm{PCoA})$ showed two distinct clusters distinguishing samples taken during early life from those taken from subsequent sampling time points, suggesting an early, founder nasopharyngeal microbiota (Figure 4a). Four batches of FP kits had been used to extract the samples and a record was made of which kit was used for each sample. Further analysis of the OTUs present indicated that samples possessed different communities depending on which kit had been used for DNA extraction (Figure 4b,d,e) and that the first two kits' associated OTUs made up the majority of their samples' reads (Figure 4d). As samples had been extracted in chronological order, rather than random order, this led to the false conclusion that OTUs from the first two kits were associated with age. OTUs driving clustering to the left in Figure $4 \mathrm{a}$ and $\mathrm{b}$ ( $P$ value of $<0.01$ ), were classified as Achromobacter, Aminobacter, Brevundimonas, Herbaspirillum, Ochrobactrum, Pedobacter, Pseudomonas, Rhodococcus, Sphingomonas and Stenotrophomonas. OTUs driving data points to the right $(P$ value of $<0.01)$ included Acidaminococcus and Ralstonia. A full list of significant OTUs is shown in Additional file 1: Table S2. Once the contaminants were identified and removed, the PCoA clustering of samples from the run no longer had a discernible pattern, showing that the contamination was the biggest driver of sample ordination (Figure 4c). New aliquots were obtained from the original sample archive and were reprocessed using a different kit lot and sequenced. The previously observed contaminant OTUs were not detected, further confirming their absence in the original 


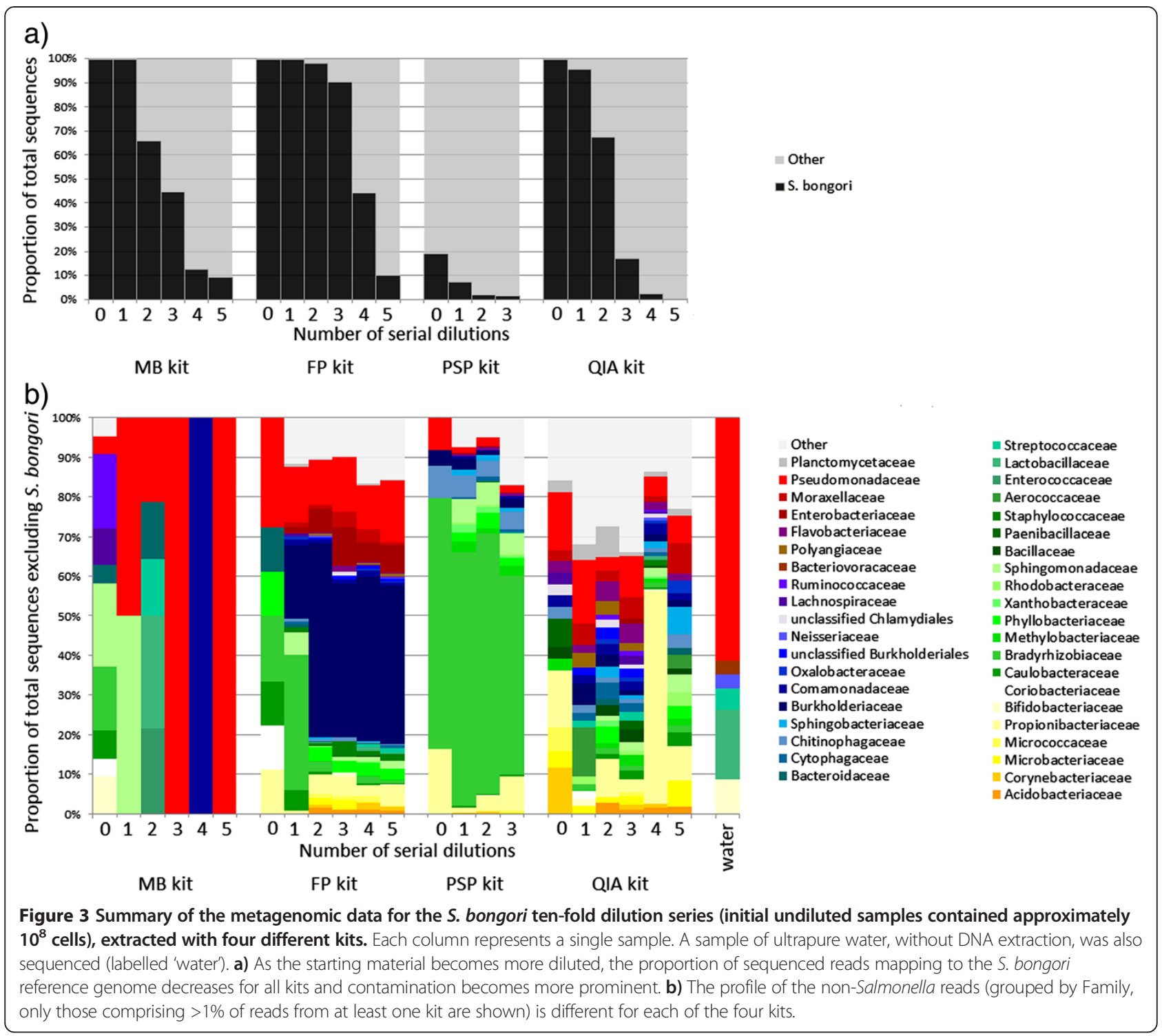

nasopharyngeal samples (manuscript in preparation, Salter S, Turner P, Turner C, Watthanaworawit W, Goldblatt D, Nosten F, Mather A, Parkhill J, Bentley S).

This dataset, therefore, serves as a case study for the significant, and potentially misleading, impact that contaminants originating from kits can have on microbiota analyses and subsequent conclusions.

\section{Discussion}

Results presented here show that contamination with bacterial DNA or cells in DNA extraction kit reagents, and the wider laboratory environment, should not only be a concern for $16 \mathrm{~S}$ rRNA gene sequencing projects, which require PCR amplification, but also for shotgun metagenomics projects.

Contaminating DNA has been reported from PCR reagents, kits and water many times [3-15,17]. The taxa identified are mostly soil- or water-dwelling bacteria and are frequently associated with nitrogen fixation. One explanation for this may be that nitrogen is often used instead of air in ultrapure water storage tanks [3]. Contamination of DNA extraction kit reagents has also been reported [16] and kit contamination is a particular challenge for low biomass studies, which may provide little template DNA to compete with that in the reagents for amplification [12,39]. Issues of contamination have plagued studies, with highprofile examples in the fields of novel virus discovery, such as in the false association of XMRV and chronic fatigue syndrome [40], and the study of ancient DNA of early humans and pathogens $[41,42]$. The microbial content of ancient ice core samples has also shown to be inconsistent when analysed by different laboratories [39].

The importance of this issue when analysing low biomass samples, despite such high-profile reports of reagent 


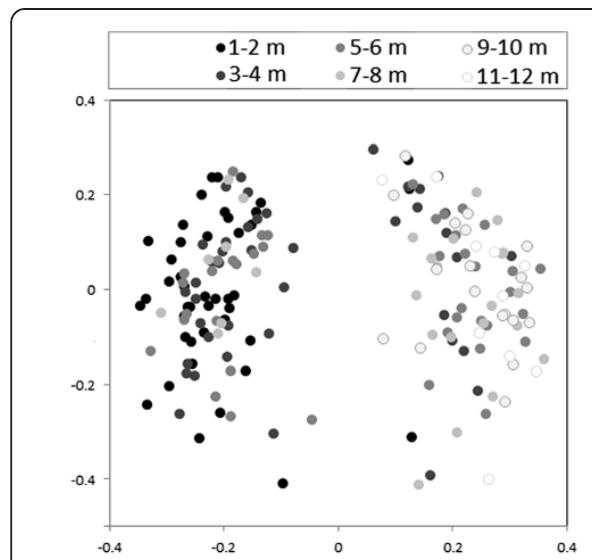

a) Full data coloured by age (months)

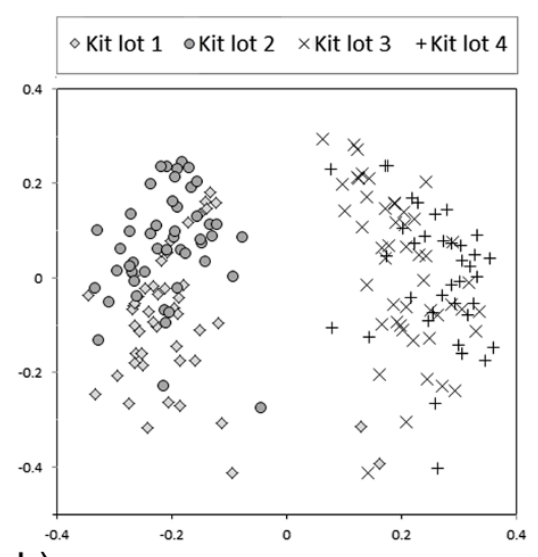

b) Full data coloured by extraction kit

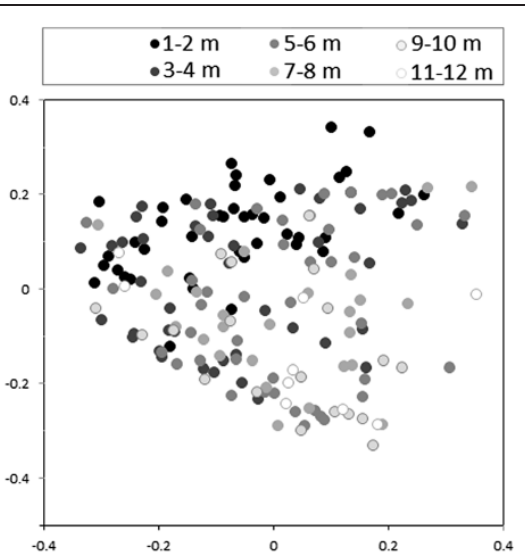

C) Contaminant OTUs removed
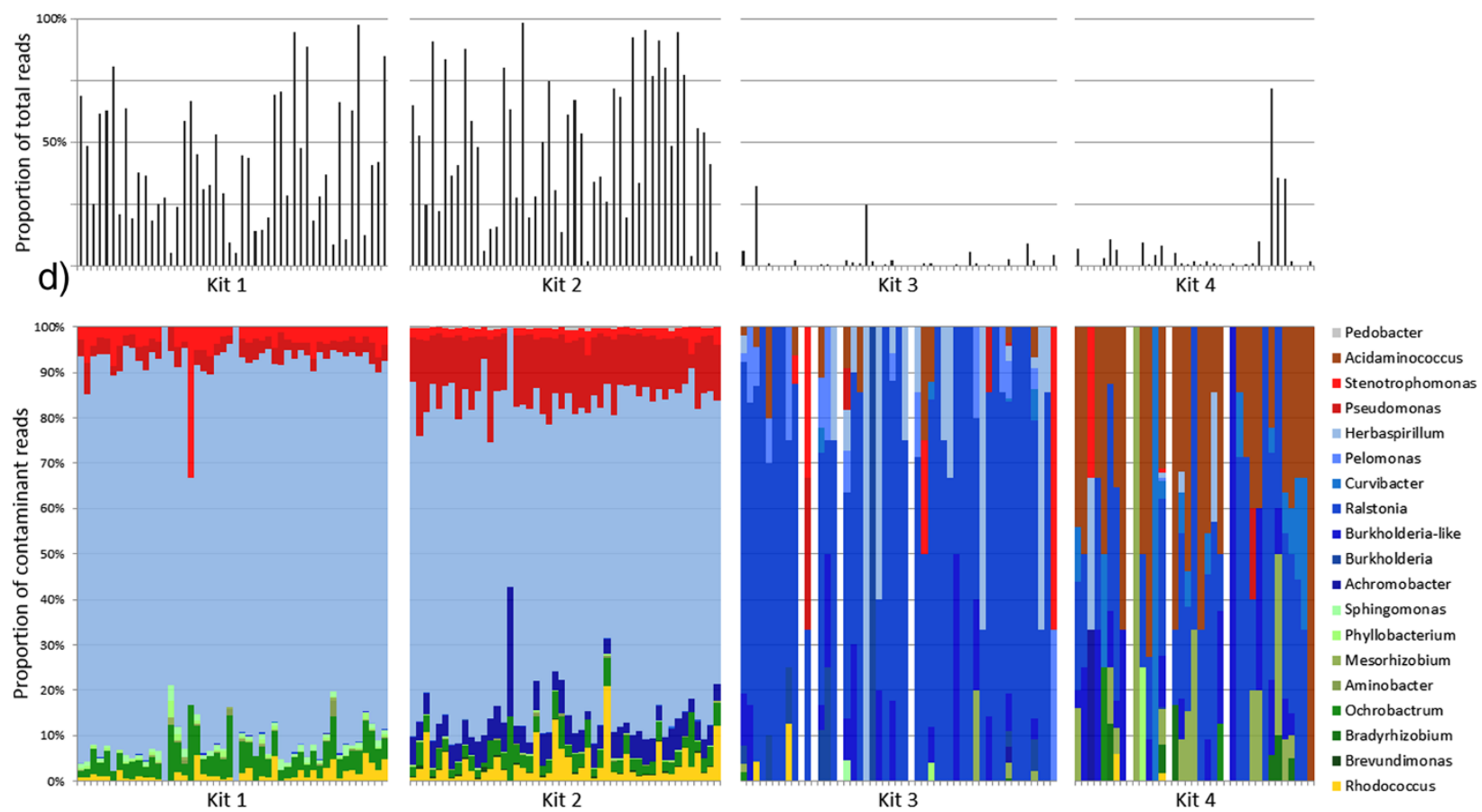

e) Profile of contaminants associated with each kit

Figure 4 Summary of the contaminant content of nasopharyngeal samples from Thailand. a) The PCoA plot appears to show age-related clustering; however, b) extraction kit lot explains the pattern better. c) When coloured by age, the plot shows the loss of the initial clustering pattern after excluding contaminant OTUs from ordination. d) The proportion of reads attributed to contaminant OTUs for each sample, demonstrating that the first two kits were the most heavily contaminated. e) Genus-level profile of contaminant OTUs for each kit used.

contamination, apparently remains underappreciated in the microbiota research community. Well-controlled studies, such as in Segal et al. who examined the lung microbiota through bronchoalveolar lavage sampling, report their results against the backdrop of copious sequenced 'background' controls [43]. However, many recent DNA sequence-based publications that describe the microbial communities of low-biomass environments do not report DNA quantification on initial samples, sequencing of negative controls or describe their contaminant removal or identification procedures. Our literature searches have indicated that there are a number of low biomass microbiota studies that report taxa, often statistically noteworthy or core members, that overlap with those we report here from our negative control kit reagents and water (shown in Table 1). While it is possible that the suspect taxa are genuinely present in these samples, in many cases they are biologically unexpected: for example, rhizosphereassociated bacteria that have been implicated in human disease [27,44]. Tellingly, Laurence et al. [18] recently 
demonstrated with an in silico analysis that Bradyrhizobium is a common contaminant of sequencing datasets including the 1000 Human Genome Project. Having demonstrated the critical impact that contaminating DNA may have on conclusions drawn from sequence-based data, it becomes important to be able to determine which observations are genuine. For environmental samples, such as soil or water, the problem of identifying contaminants requires special attention as the contaminants may be taxa that are indistinguishable from those genuinely present in the samples.

A number of methods have been devised to treat reagents in order to reduce potential contamination, including: gamma [45] or UV radiation [13,46-48], DNase treatment $[10,13,47,49-51]$, restriction digests $[10,13,47,52,53]$, caesium chloride density gradient centrifugation [10] and DNA intercalation and crosslinking with 8-methoxypsoralen [47,54], propidium monoazide [55] or ethidium monoazide [56,57]. However, tests of these methods show varying levels of success. Radiation may reduce the activity of enzymes, DNase inactivation can also damage the polymerase, restriction enzymes may introduce more contaminating DNA, and unbound DNA intercalators inhibit amplification of the intended template [56,58]. An alternative to decontamination is to preferentially amplify the template DNA using broad range primer extension PCR [59] but this, and the treatment of the PCR reagents, cannot account for contamination introduced through DNA extraction kits.

A simple in silico approach for microbiota studies is to identify contaminants that are sequenced using negative controls or contaminant databases in order to screen them out of downstream analysis $[17,60]$. In the event that contaminating organisms are discovered that are also biologically plausible and should not be excluded from the analysis, alternative approaches could be employed [61]. Statistical approaches and basic visualization to compare relative abundances or rank-order information between negative controls and samples may help determine if taxa are also real. Alternative bioinformatics approaches, such as oligotyping [62], could potentially provide fine-grained discrimination between contaminant OTUs and genuine OTUs assigned to the same genus or species. For shotgun metagenomics studies, use of strain-specific genes or use of phylogenetic information across multiple marker genes may also provide necessary discrimination. Deviation from a neutral model of community formation to compare source (kit controls) and recipient communities may also be useful in this context [63].

By adding negative sequencing controls (specifically, template-free 'blanks' processed with the same DNA extraction and PCR amplification kits as the real samples, sequenced on the same run) it is possible to identify reads originating from contamination, and distinguish them from those derived from actual constituent taxa. We have developed a set of recommendations that may help to limit the impact of reagent contamination (Box 1). With awareness of common contaminating species, careful collection of controls to cover different batches

\section{Box 1}

Recommendations to reduce the impact of contaminants in sequence-based, low-biomass microbiota studies:

1. Maximise the starting sample biomass by choice of sample type, filtration, or enrichment if possible. If microbial load is less than approximately $10^{3}$ to $10^{4}$ cells it may not be possible to obtain robust results as contamination appears to predominate. Gram staining, fluorescent in situ hybridisation (FISH), qPCR or other forms of DNA quantification prior to amplicon generation/sequencing may be useful guides in this respect. However, it must be noted that the detection limit of microscopy-based techniques may impede accurate quantification of bacterial cell numbers at very low levels, and DNA quantification measures may be impacted by contamination introduced at the DNA extraction stage.

2. Minimise risk of contamination at the point of sample collection. PCR and extraction kit reagents may be treated to reduce contaminant DNA.

3. Collect, process and sequence technical controls from each batch of sample collection/storage medium, each extraction kit, and each PCR kit concurrently with the environmental samples of interest.

4. Samples should be processed in random order to avoid creating false patterns and ideally carried out in replicates, which should be processed using different kit/reagent batches.

5. A record should be made of which sample was processed with which kit so that contamination of a particular kit lot number can be traced through to the final dataset.

6. Quantification of the negative controls and samples should be ongoing during processing in order to monitor contamination as it arises.

7. After sequencing, be wary of taxa that are present in the negative controls, taxa that are statistically associated with a particular batch of reagents, and taxa that are unexpected biologically and also coincide with previously reported contaminants, such as those listed in Table 1.

8. In the event that suspect taxa are still of interest, repeat sequencing should be carried out on additional samples using separate batches of DNA extraction kits/reagents, and, ideally, a non-sequencing-based approach (such as traditional culturing or FISH, using properly validated probe sets) should also be used to further confirm their presence in the samples. 
of sampling, extraction and PCR kits, and sequencing to monitor the content of these controls, it should be possible to effectively mitigate the impact of contaminants in microbiota studies.

\section{Conclusions}

We have shown that bacterial DNA contamination in extraction kits and laboratory reagents can significantly influence the results of microbiota studies, particularly when investigating samples containing a low microbial biomass. Such contamination is a concern for both $16 \mathrm{~S}$ rRNA gene sequencing projects, which require targeted PCR amplification and enrichment, and also for shotgun metagenomic projects which do not. Awareness of this issue by the microbiota research community is important to ensure that studies are adequately controlled and erroneous conclusions are not drawn from cultureindependent investigations.

\section{Methods \\ Samples}

For the 16S rRNA gene and metagenomic profiling, Salmonella bongori strain NCTC-12419 was cultured overnight on Luria-Bertani (LB) plates without antibiotics at $37^{\circ} \mathrm{C}$. A single colony was used to inoculate an LB broth, which was incubated with shaking at $37^{\circ} \mathrm{C}$ overnight. The $\mathrm{OD}_{600}$ upon retrieval was 1.62 , equating to around $10^{9}$ colony forming units (CFU)/ml. A total of $20 \mu$ from the culture was plated out on LB and observed to be a pure culture after overnight incubation. Five ten-fold dilutions from the starter culture were made in fresh LB. Aliquots $(1 \mathrm{ml})$ of each dilution were immediately stored at $-80^{\circ} \mathrm{C}$, and duplicates shipped on dry ice to Imperial College London and the University of Birmingham.

For the nasopharyngeal microbiota study, the samples were nasopharyngeal swabs collected from a cohort of infants in the Maela refugee camp in Thailand as described previously [38]. These were vortexed in skimmed milk, tryptone, glucose and glycerin media (STGG) medium and then stored at $-80^{\circ} \mathrm{C}$.

\section{DNA extraction}

For the 16S rRNA gene profiling work, each of the three institutes (Imperial College London, ICL; University of Birmingham, UB; Wellcome Trust Sanger Institute, WTSI) extracted DNA from the $S$. bongori aliquots in parallel, using different production batches of the FastDNA Spin Kit For Soil (MP Biomedicals, Santa Ana, California, USA kit lots \#38098, \#15447 and \#30252), according to the manufacturer's protocol. Each aliquot was extracted once at each institute. UB and WTSI extracted DNA from $200 \mu \mathrm{l}$ of sample and eluted in $50 \mu \mathrm{l}$; ICL extracted from $500 \mu \mathrm{l}$ of sample and eluted in $100 \mu \mathrm{l}$. This meant that our DNA extractions across the five-fold serial dilutions spanned a range of sample biomass from approximately $10^{8}$ down to $10^{3}$ cells.

For the metagenomic sequencing, $200 \mu \mathrm{l}$ aliquots of each $S$. bongori dilution were processed using four commercially available DNA extraction kits at UB. The final elution volume for all kits was $100 \mu \mathrm{l}$ per sample. The FP kit (lot \#38098) was used according to the manufacturer's protocol, with the exception of the homogeniser step. This was performed with a Qiagen Tissue Lyser: one minute at speed $30 /$ second followed by 30 seconds cooling the tubes on ice, repeated three times. The UltraClean Microbial DNA Isolation Kit (MO BIO Laboratories, Carlsbad, California, USA) (kit MB, lot \#U13F22) was used according to the manufacturer's protocol with the exception of homogenisation, which was replaced by 10 minutes of vortexing. The QIAmp DNA Stool Mini Kit (Qiagen, Venlo, Limburg, Netherlands) (kit QIA, lot \#145036714) was used according to the manufacturer's stool pathogen detection protocol. The heating step was at $90^{\circ} \mathrm{C}$. The PSP Spin Stool DNA Plus kit (STRATEC Molecular, Birkenfeld, Germany) (kit PSP, lot \#JB110047) was used according to the manufacturer's stool homogenate protocol. Each aliquot was processed once with each kit. All extraction reagents were included with all kits, except for ethanol added for wash steps. In addition to these samples, a negative control was included consisting of ultrapure water that had not been processed with any DNA extraction kit.

For the nasopharyngeal microbiota study, a $200 \mu \mathrm{l}$ aliquot was taken from each sample and processed with the manufacturer's vortex modification of the FP kit protocol. DNA was then shipped to WTSI for further processing and sequencing (see below).

\section{qPCR}

A standard curve was produced by cloning the near fulllength 16S rRNA gene of Vibrio natriegens DSMZ 759 amplified using primers $27 \mathrm{~F}$ and 1492R [64] into the TOPO TA vector (Life Technologies, Carlsbad, California, USA), quantifying using fluorescent assay (Quant-IT, Life Technologies) and diluting to produce a standard curve from $10^{8}$ to $10^{3}$ copies per $\mu$ l. A ViiA 7 Real-time PCR system (Life Technologies) with SYBR Fast qPCR Master Mix (KAPA Biosystems, Wilmington, Massachusetts, USA) was used to perform quantitative PCR of the V4 region of the bacterial 16S rRNA gene for each S. bongori dilution extraction (which were carried out using the FastDNA SPIN Kit for Soil (MP Biomedicals), kit lot \#15447). Primers used were: S-D-Bact-0564-a-S- 15, 5'AYTGGGYDTAAAGNG and S-D-Bact-0785-b-A-18, 5TACNVGGGTATCTAATCC [65] generating a 253 bp amplicon. Reactions $(15 \mu \mathrm{l})$ were performed in triplicate and included template-free controls. Reactions consisted of $0.3 \mu \mathrm{l}$ of $10 \mu \mathrm{M}$ dilutions of each primer, $7.5 \mu \mathrm{l}$ of SYBR 
Fast mastermix and $1.9 \mu \mathrm{l}$ of microbial DNA free PCR water (MOBIO) and $5 \mu \mathrm{l}$ of 1:5 diluted template (to avoid pipetting less than $5 \mu \mathrm{l}$ ). Cycle conditions were $90^{\circ} \mathrm{C}$ for 3 minutes followed by 40 cycles of: $95^{\circ} \mathrm{C}$ for 20 seconds, $50^{\circ} \mathrm{C}$ for 30 seconds, and $72^{\circ} \mathrm{C}$ for 30 seconds. Melt curves were run from 60 to $95^{\circ} \mathrm{C}$ over 15 minutes.

\section{Sequencing}

Samples for the $S$. bongori culture 16S rRNA gene profiling were PCR-amplified using barcoded fusion primers targeting the V1-V2 region of the gene (27f_Miseq: AATGA TACGGCGACCACCGAGATCTACAC TATGGTAATT CC AGMGTTYGATYMTGGCTCAG and 338R_MiSeq: CAAGCAGAAGACGGCATACGAGAT nnnnnnnnnnnn AGTCAGTCAG AA GCTGCCTCCCGTAGGAGT, where the $\mathrm{n}$ string represents unique 12-mer barcodes used for each sample studied, and then sequenced on the Illumina MiSeq platform using $2 \times 250$ bp cycles. The PCR amplification was carried out with the Q5 HighFidelity PCR kit (New England Biolabs, Ipswich, Massachusetts, USA) at WTSI, ICL and UB, using fresh reagents and consumables, autoclaved microcentrifuge tubes, filtered pipette tips, and performed in a hood to reduce the risk of airborne contamination. Each sample was amplified with both 20 and 40 PCR cycles under the following conditions: $94^{\circ} \mathrm{C}$ for 30 seconds, $53^{\circ} \mathrm{C}$ for 30 seconds, $68^{\circ} \mathrm{C}$ for 2 minutes. Negative controls in the form of a PCR-amplified ultrapure water sample were included for each batch. PCR products were visualised on an agarose gel: bands were visible for all 40 cycle samples and the first four dilutions of the 20 cycle samples. Data are deposited under ENA project accession EMBL: ERP006737; sample details and individual accession numbers are detailed in Additional file 1: Table S1a.

For metagenomic sequencing, all samples were quantified using Nanodrop (Thermo Scientific, Waltham, Massachusetts, USA) and Qubit (Life Technologies) machines, and did not need to be diluted before Illumina Nextera XT library preparation (processed according to the manufacturer's protocol). Libraries were multiplexed on the Illumina MiSeq in paired 250-base mode following a standard MiSeq wash protocol. Data are deposited under ENA project accession EMBL: ERP006808. Sample details and individual accession numbers are provided in Additional file 1: Table S1b.

For the nasopharyngeal microbiota study, DNA extractions from 182 swabs were PCR-amplified and barcoded for sequencing the $16 \mathrm{~S}$ rRNA gene V3-V5 region on the 454 platform as described previously [66].

\section{Sequence analysis}

For the 16S rRNA gene profiling, data were processed using mothur [67]. The mothur MiSeq SOP [68] was followed with the exception of screen.seqs, which used the maximum length of the 97.5 percentile value, and chimera checking, which was performed with Perseus [69] instead of UCHIME. Read counts post-processing and the number of genus-level phylotypes present in each sample are shown in Additional file 1: Table S1a.

For the metagenomic profiling, reads were quality checked and trimmed for low-quality regions and adaptor sequences using Trimmomatic [70]. Similarity sequencing for taxonomic assignments was performed using LAST in six-frame translation mode against the Microbial RefSeq protein database [71]. Taxonomic assignments were determined with MEGAN, which employs a lowest common ancestor (LCA) to taxonomic assignments, using settings Min Support 2, Min Score 250, Max Expected 0.1, Top Percent 10.0 [72].

For the nasopharyngeal microbiota study, the data were processed, cleaned and analysed using the mothur Schloss SOP [73] and randomly subsampled to 200 sequence reads per sample. As part of the contamination identification procedure, the metastats package [74] within mothur was used to identify OTUs that were significantly associated with each extraction kit batch. Jaccard PCoA plots were generated with mothur, comparing the dataset with and without these flagged OTUs included.

\section{Additional file}

Additional file 1: Figure S1 (16S rRNA gene profile of S. bongori amplified with 20 PCR cycles), Figure S2 (genus-level phylotypes that are likely to have originated during DNA extractions), Tables S1a and S1b (accession numbers and read counts for $16 \mathrm{~S}$ and metagenomic data respectively) and Table S2 (OTUs with significant correlation in Figures $4 \mathrm{~b}$ and $4 \mathrm{c}$ ).

\section{Competing interests}

The authors declare that they have no competing interests.

\section{Authors' contributions}

SJS, MJC, NJL and AWW devised experiments. SJS, ET, STC and NJL performed experiments. SJS, MJC, NJL and AWW analysed data and prepared figures. PT provided data demonstrating the impact of extraction kit contaminants. WOC, MFM, NJL and JP provided resources, guidance and support. SJS, MJC, NJL and AWW wrote the paper. All authors read and approved the final manuscript.

\section{Acknowledgements}

SJS, JP, AWW and sequencing costs were supported by the Wellcome Trust (grant number 098051). MJC was supported by a Wellcome Trust Centre for Respiratory Infection Basic Science Fellowship. STC is funded by the National Institute for Health Research (NIHR). WOC and MFM are supported by a Wellcome Trust Joint Senior Investigator's Award, which also supports EMT. PT was supported by a Wellcome Trust Clinical Training Fellowship (grant number 083735/Z/07/Z). NJL is supported by a Medical Research Council Special Training Fellowship in Biomedical Informatics. AWW and The Rowett Institute of Nutrition and Health, University of Aberdeen receive core funding support from the Scottish Government Rural and Environmental Science and Analysis Service (RESAS). The views expressed are those of the authors and not necessarily those of the Wellcome Trust, the NHS, the NIHR or the Department of Health. We would like to thank the Wellcome Trust Sanger Institute's core sequencing team, Paul Scott for his assistance in the laboratory and for providing a list of 
contaminants derived from multiple displacement amplification kits, Phil James for assistance with $\mathrm{gPCR}$, and Christine Boinett for $\mathrm{R}$ advice.

\section{Author details}

'Pathogen Genomics Group, Wellcome Trust Sanger Institute, Hinxton, UK. ${ }^{2}$ Molecular Genetics and Genomics, National Heart and Lung Institute, Imperial College London, London, UK. ${ }^{3}$ Institute of Microbiology and Infection, University of Birmingham, Birmingham, UK. ${ }^{4}$ Shoklo Malaria Research Unit, Mahidol-Oxford Tropical Medicine Research Unit, Faculty of Tropical Medicine, Mahidol University, Mae Sot, Thailand. ${ }^{5}$ Centre for Tropical Medicine, Nuffield Department of Medicine, University of Oxford, Oxford, UK. ${ }^{6}$ Microbiology Group, Rowett Institute of Nutrition and Health, University of Aberdeen, Aberdeen, UK.

Received: 15 July 2014 Accepted: 13 October 2014

Published online: 12 November 2014

\section{References}

1. Kunin $\mathrm{V}$, Engelbrektson $\mathrm{A}$, Ochman $\mathrm{H}$, Hugenholtz $\mathrm{P}$ : Wrinkles in the rare biosphere: pyrosequencing errors can lead to artificial inflation of diversity estimates. Environ Microbiol 2010, 12:118-123.

2. Fv W, Göbel UB, Stackebrandt E: Determination of microbial diversity in environmental samples: pitfalls of PCR-based rRNA analysis. FEMS Microbiol Rev 1997, 21:213-229.

3. Kulakov LA, McAlister MB, Ogden KL, Larkin MJ, O'Hanlon JF: Analysis of bacteria contaminating ultrapure water in industrial systems. Appl Environ Microbiol 2002, 68:1548-1555.

4. McAlister MB, Kulakov LA, O'Hanlon JF, Larkin MJ, Ogden KL: Survival and nutritional requirements of three bacteria isolated from ultrapure water J Ind Microbiol Biotechnol 2002, 29:75-82.

5. Kéki Z, Grébner K, Bohus V, Márialigeti K, Tóth EM: Application of special oligotrophic media for cultivation of bacterial communities originated from ultrapure water. Acta Microbiol Immunol Hung 2013, 60:345-357.

6. Bohus V, Kéki Z, Márialigeti K, Baranyi K, Patek G, Schunk J, Tóth EM: Bacterial communities in an ultrapure water containing storage tank of a power plant. Acta Microbiol Immunol Hung 2011, 58:371-382.

7. McFeters GA, Broadaway SC, Pyle BH, Egozy Y: Distribution of bacteria within operating laboratory water purification systems. Appl Environ Microbiol 1993, 59:1410-1415.

8. Nogami T, Ohto T, Kawaguchi O, Zaitsu Y, Sasaki S: Estimation of bacterial contamination in ultrapure water: application of the anti-DNA antibody. Anal Chem 1998, 70:5296-5301.

9. Shen H, Rogelj S, Kieft TL: Sensitive, real-time PCR detects low-levels of contamination by Legionella pneumophila in commercial reagents. Mol Cell Probes 2006, 20:147-153.

10. Rand $\mathrm{KH}$, Houck H: Taq polymerase contains bacterial DNA of unknown origin. Mol Cell Probes 1990, 4:445-450.

11. Maiwald M, Ditton HJ, Sonntag HG, von Knebel Doeberitz M: Characterization of contaminating DNA in Taq polymerase which occurs during amplification with a primer set for Legionella 5S ribosomal RNA. Mol Cell Probes 1994, 8:11-14.

12. Tanner MA, Goebel BM, Dojka MA, Pace NR: Specific ribosomal DNA sequences from diverse environmental settings correlate with experimental contaminants. App/ Environ Microbio/ 1998, 64:3110-3113.

13. Corless CE, Guiver M, Borrow R, Edwards-Jones V, Kaczmarski EB, Fox AJ: Contamination and sensitivity issues with a real-time universal 16S rRNA PCR. J Clin Microbiol 2000, 38:1747-1752.

14. Grahn N, Olofsson M, Ellnebo-Svedlund K, Monstein HJ, Jonasson J: Identification of mixed bacterial DNA contamination in broad-range PCR amplification of $16 \mathrm{~S}$ rDNA V1 and V3 variable regions by pyrosequencing of cloned amplicons. FEMS Microbiol Lett 2003, 219:87-91.

15. Newsome T, Li BJ, Zou N, Lo SC: Presence of bacterial phage-like DNA sequences in commercial Taq DNA polymerase reagents. J Clin Microbiol 2004, 42:2264-2267.

16. Mohammadi T, Reesink HW, Vandenbroucke-Grauls CM, Savelkoul PH: Removal of contaminating DNA from commercial nucleic acid extraction kit reagents. J Microbiol Methods 2005, 61:285-288.

17. Barton HA, Taylor NM, Lubbers BR, Pemberton AC: DNA extraction from low-biomass carbonate rock: an improved method with reduced contamination and the low-biomass contaminant database. J Microbiol Methods 2006, 66:21-31.
18. Laurence M, Hatzis C, Brash DE: Common contaminants in nextgeneration sequencing that hinder discovery of low-abundance microbes. PLoS One 2014, 9:e97876.

19. Oberauner L, Zachow C, Lackner S, Högenauer C, Smolle KH, Berg G: The ignored diversity: complex bacterial communities in intensive care units revealed by 16S pyrosequencing. Sci Rep 2013, 3:1413.

20. La Duc MT, Kern R, Venkateswaran K: Microbial monitoring of spacecraft and associated environments. Microb Ecol 2004, 47:150-158.

21. Ling Z, Liu X, Luo Y, Yuan L, Nelson KE, Wang Y, Xiang C, Li L: Pyrosequencing analysis of the human microbiota of healthy Chinese undergraduates. BMC Genomics 2013, 14:390.

22. Benítez-Páez A, Álvarez M, Belda-Ferre P, Rubido S, Mira A, Tomás I: Detection of transient bacteraemia following dental extractions by $16 \mathrm{~S}$ rDNA pyrosequencing: a pilot study. PLoS One 2013, 8:e57782.

23. Amar J, Serino M, Lange C, Chabo C, lacovoni J, Mondot S, Lepage P, Klopp C, Mariette J, Bouchez O, Perez L, Courtney M, Marre M, Klopp P, Lantieri O, Doré J, Charles M, Balkau B, Burcelin R, D.E.S.I.R. Study Group: Involvement of tissue bacteria in the onset of diabetes in humans: evidence for a concept. Diabetologia 2011, 54:3055-3061.

24. Branton WG, Ellestad KK, Maingat F, Wheatley BM, Rud E, Warren RL, Holt RA, Surette MG, Power C: Brain microbial populations in HIV/AIDS: a-proteobacteria predominate independent of host immune status. PLoS One 2013, 8:e54673.

25. Borewicz K, Pragman AA, Kim HB, Hertz M, Wendt C, Isaacson RE: Longitudinal analysis of the lung microbiome in lung transplantation. FEMS Microbiol Lett 2013, 339:57-65.

26. Dong Q, Brulc JM, lovieno A, Bates B, Garoutte A, Miller D, Revanna KV, Gao X, Antonopoulos DA, Slepak VZ, Shestopalov VI: Diversity of bacteria at healthy human conjunctiva. Invest Ophthalmol Vis Sci 2011, 52:5408-5413.

27. Xuan C, Shamonki JM, Chung A, DiNome ML, Chung M, Sieling PA, Lee DJ: Microbial dysbiosis is associated with human breast cancer. PLOS One 2014, 9:e83744.

28. Kuehn JS, Gorden PJ, Munro D, Rong R, Dong Q, Plummer PJ, Wang C, Phillips GJ: Bacterial community profiling of milk samples as a means to understand culture-negative bovine clinical mastitis. PLOS One 2013, 8:e61959.

29. Srinivas G, Möller S, Wang J, Künzel S, Zillikens D, Baines JF, Ibrahim SM: Genome-wide mapping of gene-microbiota interactions in susceptibility to autoimmune skin blistering. Nat Commun 2013, 4:2462

30. Boissière A, Tchioffo MT, Bachar D, Abate L, Marie A, Nsango SE, Shahbazkia $\mathrm{HR}$, Awono-Ambene PH, Levashina EA, Christen R, Morlais I: Midgut microbiota of the malaria mosquito vector Anopheles gambiae and interactions with Plasmodium falciparum infection. PLOS Pathog 2012, 8:e1002742.

31. McKenzie VJ, Bowers RM, Fierer N, Knight R, Lauber CL: Co-habiting amphibian species harbor unique skin bacterial communities in wild populations. ISME J 2012, 6:588-596.

32. Carlos C, Torres TT, Ottoboni LM: Bacterial communities and speciesspecific associations with the mucus of Brazilian coral species. Sci Rep 2013, 3:1624.

33. Cheng XY, Tian XL, Wang YS, Lin RM, Mao ZC, Chen N, Xie BY: Metagenomic analysis of the pinewood nematode microbiome reveals a symbiotic relationship critical for xenobiotics degradation. Sci Rep 2013, 3:1869.

34. Davidson SK, Powell R, James S: A global survey of the bacteria within earthworm nephridia. Mol Phylogenet Evol 2013, 67:188-200.

35. Knowlton C, Veerapaneni R, D'Elia T, Rogers SO: Microbial analyses of ancient ice core sections from Greenland and Antarctica. Biology (Basel) 2013, 2:206-232

36. Shtarkman YM, Koçer ZA, Edgar R, Veerapaneni RS, D'Elia T, Morris PF, Rogers SO: Subglacial Lake Vostok (Antarctica) accretion ice contains a diverse set of sequences from aquatic, marine and sediment-inhabiting bacteria and eukarya. PLoS One 2013, 8:e67221.

37. DeLeon-Rodriguez N, Lathem TL, Rodriguez-R LM, Barazesh JM, Anderson BE, Beyersdorf AJ, Ziemba LD, Bergin M, Nenes A, Konstantinidis KT: Microbiome of the upper troposphere: Species composition and prevalence, effects of tropical storms, and atmospheric implications. Proc Natl Acad Sci U S A 2013, 110:2575-2580.

38. Turner $P$, Turner $C$, Jankhot A, Helen N, Lee SJ, Day NP, White NJ, Nosten F, Goldblatt D: A longitudinal study of Streptococcus pneumoniae carriage in a cohort of infants and their mothers on the Thailand-Myanmar border. PLoS One 2012, 7:e38271 
39. Willerslev E, Hansen AJ, Poinar HN: Isolation of nucleic acids and cultures from fossil ice and permafrost. Trends Ecol Evol 2004, 19:141-147.

40. Kearney MF, Spindler J, Wiegand A, Shao W, Anderson EM, Maldarelli F, Ruscetti FW, Mellors JW, Hughes SH, Le Grice SF, Coffin JM: Multiple sources of contamination in samples from patients reported to have XMRV infection. PLoS One 2012, 7:e30889.

41. Cooper A, Poinar HN: Ancient DNA: do it right or not at all. Science 2000, 289:1139.

42. Roberts C, Ingham S: Using ancient DNA analysis in palaeopathology: a critical analysis of published papers, with recommendations for future work. Int J Osteoarchaeol 2008, 18:600-613.

43. Segal LN, Alekseyenko AV, Clemente JC, Kulkarni R, Wu B, Chen H, Berger KI, Goldring RM, Rom WN, Blaser MJ, Weiden MD: Enrichment of lung microbiome with supraglottic taxa is associated with increased pulmonary inflammation. Microbiome 2013, 1:19.

44. Bhatt AS, Freeman SS, Herrera AF, Pedamallu CS, Gevers D, Duke F, Jung J, Michaud M, Walker BJ, Young S, Earl AM, Kostic AD, Ojesina Al, Hasserjian R, Ballen KK, Chen YB, Hobbs G, Antin JH, Soiffer RJ, Baden LR, Garrett WS, Hornick JL, Marty FM, Meyerson M: Sequence-based discovery of Bradyrhizobium enterica in cord colitis syndrome. N Engl J Med 2013, 369:517-528.

45. Deragon JM, Sinnett D, Mitchell G, Potier M, Labuda D: Use of gamma irradiation to eliminate DNA contamination for PCR. Nucleic Acids Res 1990, 18:6149

46. Sarkar G, Sommer SS: Shedding light on PCR contamination. Nature 1990, 343:27.

47. Klaschik S, Lehmann LE, Raadts A, Hoeft A, Stuber F: Comparison of different decontamination methods for reagents to detect low concentrations of bacterial 16S DNA by real-time-PCR. Mol Biotechnol 2002, 22:231-242.

48. Tamariz J, Voynarovska K, Prinz M, Caragine T: The application of ultraviolet irradiation to exogenous sources of DNA in plasticware and water for the amplification of low copy number DNA. J Forensic Sci 2006, 51:790-794

49. Hilali F, Saulnier P, Chachaty E, Andremont A: Decontamination of polymerase chain reaction reagents for detection of low concentrations of 16S rRNA genes. Mol Biotechnol 1997, 3:207-216.

50. Heininger A, Binder M, Ellinger A, Botzenhart $K$, Unertl K, Döring G: DNase pretreatment of master mix reagents improves the validity of universal 16S rRNA gene PCR results. J Clin Microbiol 2003, 41:1763-1765.

51. Silkie SS, Tolcher MP, Nelson KL: Reagent decontamination to eliminate falsepositives in Escherichia coli qPCR. J Microbiol Methods 2008, 72:275-282.

52. Carroll NM, Adamson P, Okhravi N: Elimination of bacterial DNA from Taq DNA polymerases by restriction endonuclease digestion. J Clin Microbiol 1999, 37:3402-3404.

53. Mohammadi T, Reesink HW, Vandenbroucke-Grauls CM, Savelkoul PH: Optimization of real-time PCR assay for rapid and sensitive detection of eubacterial 16S ribosomal DNA in platelet concentrates. $J$ Clin Microbiol 2003, 41:4796-4798.

54. Hughes MS, Beck LA, Skuce RA: Identification and elimination of DNA sequences in Taq DNA polymerase. J Clin Microbiol 1994, 32:2007-2008.

55. Vaishampayan P, Probst AJ, La Duc MT, Bargoma E, Benardini JN, Andersen GL, Venkateswaran K: New perspectives on viable microbial communities in low-biomass cleanroom environments. ISME J 2013, 7:312-324.

56. Rueckert A, Morgan HW: Removal of contaminating DNA from polymerase chain reaction using ethidium monoazide. $J$ Microbiol Methods 2007, 68:596-600.

57. Patel P, Garson JA, Tettmar Kl, Ancliff S, McDonald C, Pitt T, Coelho J, Tedder RS: Development of an ethidium monoazide-enhanced internally controlled universal $16 \mathrm{~S}$ rDNA real-time polymerase chain reaction assay for detection of bacterial contamination in platelet concentrates. Transfusion 2012, 52:1423-1432.

58. Champlot S, Berthelot C, Pruvost M, Bennett EA, Grange T, Geigl EM: An efficient multistrategy DNA decontamination procedure of PCR reagents for hypersensitive PCR applications. PLoS One 2010, 5:e13042.

59. Chang SS, Hsu HL, Cheng JC, Tseng CP: An efficient strategy for broad-range detection of low abundance bacteria without DNA decontamination of PCR reagents. PLOS One 2011, 6:e20303.

60. Bonfert T, Csaba G, Zimmer R, Friedel CC: Mining RNA-Seq data for infections and contaminations. PLoS One 2013, 8:e73071.

61. Knights D, Kuczynski J, Charlson ES, Zaneveld J, Mozer MC, Collman RG, Bushman FD, Knight R, Kelley ST: Bayesian community-wide cultureindependent microbial source tracking. Nat Methods 2011, 8:761-763.
62. Eren AM, Maignen L, Sul WJ, Murphy LG, Grim SL, Morrison HG, Sogin ML: Oligotyping: differentiating between closely related microbial taxa using 16S rRNA gene data. Methods Ecol Evol 2013, 4:1111-1119.

63. Morris A, Beck JM, Schloss PD, Campbell TB, Crothers K, Curtis JL, Flores SC, Fontenot AP, Ghedin E, Huang L, Jablonski K, Kleerup E, Lynch SV, Sodergren E, Twigg H, Young VB, Bassis CM, Venkataraman A, Schmidt TM, Weinstock GM: Comparison of the respiratory microbiome in healthy nonsmokers and smokers. Am J Respir Crit Care Med 2013, 187:1067-1075.

64. Lane DJ: 16S/23S rRNA sequencing. In Nucleic Acid Techniques in Bacterial Systematics. Edited by Stackebrandt E, Goodfellow M. Chichester, UK: Wiley; 1991:115-175.

65. Klindworth A, Pruesse E, Schweer T, Peplies J, Quast C, Horn M, Glöckner FO: Evaluation of general $16 \mathrm{~S}$ ribosomal RNA gene PCR primers for classical and next-generation sequencing-based diversity studies. Nucleic Acids Res 2013, 41:e1.

66. Cooper P, Walker AW, Reyes J, Chico M, Salter SJ, Vaca M, Parkhill J: Patent human infections with the whipworm, Trichuris trichiura, are not associated with alterations in the faecal microbiota. PLOS One 2013, 8:e76573.

67. Schloss PD, Westcott SL, Ryabin T, Hall JR, Hartmann M, Hollister EB, Lesniewski RA, Oakley BB, Parks DH, Robinson CJ, Sahl JW, Stres B, Thallinger GG, Van Horn DJ, Weber CF: Introducing mothur: open-source, platform-independent, community-supported software for describing and comparing microbial communities. Appl Environ Microbiol 2009, 75:7537-7541.

68. Kozich JJ, Westcott SL, Baxter NT, Highlander SK, Schloss PD: Development of a dual-index sequencing strategy and curation pipeline for analyzing amplicon sequence data on the MiSeq Illumina sequencing platform. Appl Environ Microbiol 2013, 79:5112-5120.

69. Quince C, Lanzen A, Davenport RJ, Turnbaugh PJ: Removing noise from pyrosequenced amplicons. BMC Bioinformatics 2011, 12:38.

70. Bolger AM, Lohse M, Usadel B: Trimmomatic: a flexible trimmer for Illumina sequence data. Bioinformatics 2014, 30:2114-2120.

71. Kiełbasa SM, Wan R, Sato K, Horton P, Frith MC: Adaptive seeds tame genomic sequence comparison. Genome Res 2011, 21:487-493.

72. Huson DH, Mitra S, Ruscheweyh HJ, Weber N, Schuster SC: Integrative analysis of environmental sequences using MEGAN4. Genome Res 2011, 21:1552-1560.

73. Schloss PD, Gevers D, Westcott SL: Reducing the effects of PCR amplification and sequencing artifacts on 16S rRNA-based studies. PLoS One 2011, 6:e27310

74. White JR, Nagarajan N, Pop M: Statistical methods for detecting differentially abundant features in clinical metagenomic samples. PLoS Comput Biol 2009, 5:e1000352.

doi:10.1186/s12915-014-0087-z

Cite this article as: Salter et al.: Reagent and laboratory contamination can critically impact sequence-based microbiome analyses. BMC Biology 2014 12:87.

\section{Submit your next manuscript to BioMed Central and take full advantage of:}

- Convenient online submission

- Thorough peer review

- No space constraints or color figure charges

- Immediate publication on acceptance

- Inclusion in PubMed, CAS, Scopus and Google Scholar

- Research which is freely available for redistribution

Submit your manuscript at www.biomedcentral.com/submit

C BioMed Central 